\title{
The evolution, application, and future of macroappraisal
}

\section{Candace Loewen}

Published online: 19 January 2007

(C) Springer Science+Business Media B.V. 2007

\section{Erratum to: Archival Science \\ DOI: 10.1007/s10502-005-9003-1}

The asterisk at the end of the article title leads the reader to a note at the bottom of the page which is incorrect and should be deleted.

The online version of the original article can be found at http://dx.doi.org/10.1007/s10502-005-9003-1

C. Loewen $(\bowtie)$

Library and Archives Canada, Ottawa, ON, Canada K1A 0N4

e-mail: candace.loewen@lac-bac.gc.ca 